\title{
ADULT FILARIA (WUCHERERIA) BANCROFTI IN THE ANTERIOR CHAMBER
}

\author{
BY \\ Lieut.-Col. R. E. Wright, C.I.E., I.M.S. \\ SUPERINTENDENT, GOVERNMENT OPHTHALMIC \\ HOSPITAL, MADRAS
}

IN the Brit. Jl. of Ophthal. for September, 1932, my colleague, Dr. K. Koman Nayar, published a record of the removal of an adult filarial worm from the eye of a patient from the west coast of India. Unfortunately the specimen was lost at the time of operation and neither its sex nor identity could be verified. Although it was surmised at the time that the worm was filaria bancrofti there is now room for doubt in view of recent work on filariasis in Travancore: Dr. Jacocks of the Rockefeller Foundation and his assistants; and Mr. M.O.' '. Lyengar, Government Entomologist, Travancore, have shown that in the urban area of Trivandrum filaria (W) bancrofti is the responsible agent; Iyengar, working in two rural coastal areas of North Travancore, found that another type of infection is prevalent in these areas due to filaria malayi, a new species first described by Brug in 1927. In 1914 Cruickshank and the present writer working in British Cochin, a coastal area not far north of the above mentioned coastal localities, concluded that we were dealing with only one type of filarial infection, namely, that due to filaria (W) bancrofti. At that time a case had not been made out for the existence of filaria malayi. Although it now appears possible that we were dealing with two infections simultaneously occurring in the same place, neither the morphological minutiae of our microfilariae, nor the details of our feeding experiments afford enough evidence to determine this point: The adult filaria malayi has never been found and the existence of the species depends on morphological differences in the microfilariae, feeding experiments with different species of transmitting mosquitoes, and on the examination of the prevalent mosquitoes collected under natural conditions in the endemic areas, with regard to the development of the larval filariae within them. It is generally accepted that culex fatigans is the carrier of filaria (W) bancrofti in India and it appears from Iyengar's work that Mansonia (Mansonoides) annuliferus (Theob) is the transmitter of filaria malayi on the west coast. Although our mosquito survey showed the presence of Mansonoides septemguttata we did not attempt feeding experiments with this species, nor did we dissect specimens which might have been naturally infected. The 
abnormal development of the larval forms in some of the culex fatigans fed on patients harbouring microfilariae supposed by us to have been bancrofti, is suggestive of the possibility that these patients had filaria malayi in their blood. Be this as it may, the bulk of the filariasis in Cochin is probably due to filaria (W) bancrofti. It has recently been suggested, however, that some of the adult worms which we obtained from patients in Cochin may be filaria malayi. In all, we recovered five complete worms and portions of at least six others from two patients, and stated that these "if not bancrofti at least very closely resembled this species." We described them in detail as they appeared "to differ in minor points from the descriptions at our disposal." Unfortunately this collection of worms is no longer available for further reference as the portions of it which we presented to various laboratories have been lost, but the detailed morphological points and measurements are given in the original communication, and all the original drawings are still preserved.

A comparison of the various features described by us show such slight variations from more recent descriptions by Mapleston (1929) of adult worms accepted as filaria (W) bancrofti, that until known adult specimens of filaria malayi are obtained and found to show only such slight variations from previously described types, our Cochin worms must be regarded as bancrofti. This view would also be supported by fresh finds of adult filarial worms collected in areas where the carrier of filaria malayi does not exist, in which trivial variations from type (such as in the number of the anal papillae, etc.,) were present. The entomological interest with which the present specimen may be regarded is obvious. It is an adult male filarial worm obtained from a patient who had never been outside an area in which Mansonoides is absent, but in which culex fatigans is common. Unfortunately microfilariae were not present in his blood, but they may yet appear and he will be examined from time to time with a view to finding them. This worm has not yet been worked out, but in due course a detailed description will be sent to the Indian Journal of Medical Research. Meantime it may be assumed to be filaria (W) bancrofti.

The clinical notes are as follows :-

A. P., male, Hindu, age 25 years, residing in Madras (George Town), was admitted on February 21, 1934, for iritis, right eye. There was a fine exudate on the pupillary border and flocculent deposit at the bottom of the anterior chamber with fine K.P. He was put on sodii salicyl. and atropine ointment; the usual blood tests, etc., were ordered. Right eye vision $=6 / 18$; left eye vision $=6 / 6$.

There were fine vitreous opacities, the disc was dull red indistinctly seen through the haze, details of the retina not clear. There 
were two definite rounded haemorrhages each about $1 / 4$ disc diameter just beyond the macular area, one superior temporal the other inferior temporal in direction.

On March 5, 1934, in a routine examination a filarial worm was seen moving rapidly in the anterior chamber. The worm was easily visible to the naked eye because of its movements and a fluorescent sheen which gave rise to scintillations as it rapidly lashed and wound round itself in a loose tangle of coils. By the time the worm had been discovered it was no longer possible to get a sharp view of the fundus. With the corneal microscope fluorescence of the worm was very obvious at certain angles, although it was translucent or faintly opaque in other positions. Little could be made out even when the movements slowed down - as they did periodically-except that the tail was carried in the position characteristic of the male bancrofti; a sharp complete loop being maintained just in front of the anus. There were punctate brownish deposits all over the endothelium and fine dust-like floaters in the aqueous.

The patient did not give a history of filarial fever, did not show any filarial swellings, nor were microfilariae present in his night blood. As indicated in the entomological note above, the case was much more than an ophthalmological curiosity, but it presented another even greater interest. Filariasis is one of the great economic health problems of India. Up to the present there have been no practical proposals for its prevention or cure. In this patient I saw an opportunity to try the effect of drugs on an adult worm which could be kept under abservation in natural conditions. The difficulty was to decide what drugs to try. Almost every drug which might have an influence on the nemathelminthes has at one time or another been tried in filariasis without effect. Ordinarily there is no way of checking the result on the adult except by noting the cessation of attacks of filarial fever, a sudden disappearance of microfilariae from the blood, or a cessation of elephantoid and glandular swellings and the possible subsidence of swellings already existing. I decided to try menthol for reasons which need not be given here, but was unable to find any record in standard works as to the maximum dosage. Dr. J. C. David, Professor of Pharmacology, Medical College, Madras, kindly undertook to work out the dose for dogs; meantime the patient was given one grain intramuscularly. Next morning the worm was not to be seen, but it reappeared in full vigour from the posterior segment after some hours. As the intra-ocular exudates were rapidly increasing it seemed unjustifiable to postpone operation, and it was decided to remove the worm, keep it alive if possible, and try the effect of drugs outside the body. (We eventually heard that dogs were unaffected by five grains of menthol intravenously.)

On March 8, 1934, the removal was undertaken. Dr. Koman 
Nayar, who assisted me, described the difficulties he experienced in his case; when the anterior chamber was opened it simply disappeared, and so elaborate precautions were taken to avoid a repitition of this misfortune. A black mask was cramped on to the lid margins by means of the speculum. A black papier mâché dish full of warm saline was kept ready, and suitable pipette apparatus with which to receive it as it made exit. Pantocaine in small amount was used lest the usual cocainization should paralyse or kill the worm and prevent our taking it alive. A small keratome incision was made in the cornea, not more than $2 \mathrm{~mm}$. in length on the deep aspect. The instrument was quickly withdrawn without the loss of more than a trace of aqueous. In the fraction of a second which this withdrawal took the worm disappeared, and neither operator, assistant, nor any of the numerous doctors present around the table could say where it had gone; all thought that it came out, but the most painstaking search did not reveal its whereabouts. With feelings of great disappointment the various paraphernalia were collected and placed in the dish of warm saline and sent to the laboratory whither I followed in about half an hour, not very hopefully, to renew the search. The various articles in the tray were systematically examined under the binocular dissecting microscope with powerful illumination and just as I was about to relinquish the search, I found the worm in a fold on the black mask. In spite of its length-about an inch-it could hardly have been discovered with the naked eye; every hair and stray piece of cotton fibre in the tray demanded scrutiny.

This somewhat lengthy description is given to emphasize the difficulties attendant on retrieving such a specimen for the benefit of others who may come across a filarial worm in the anterior chamber. It seems unlikely that the worm was merely washed out with escaping aqueous - the escape was too minute-but rather, that finding itself near an aperture where momentarily there was a forward movement of fluid, it exercised its instinctive urge to push on. When found it was alive, but sluggish; nearly two hours had elapsed since it left the eye. It was immediately placed in a watch glass of warm saline to which some fresh human serum was added and shortly afterwards transferred to a large volume of warm Locke's saline solution at $37^{\circ} \mathrm{C}$. in the incubator. No further opportunity of trying the effect of drugs on its vitality was forthcoming as next morning it was dead. Presumably physical factors peculiar to the body fluids under natural conditions were essential to its existence; even a tissue fluid substitute at body temperature outside the body was insufficient for its vitality. The specimen was stored in 70 per cent. alcohol with 5 per cent. glycerine for further examination in due course.

The patient was discharged on April 23, 1934. At this time 
right eye vision $=6 / 6$, left eye vision $=6 / 6$. There were fine dustlike vitreous opacities in the right eye. The disc presented the appearance of a subsiding neuritis with commencing atrophy, the arteries were narrow and thread-like, the peripapillary retina a dull grey. The haemorrhages had disappeared.

\title{
REFERENCES
}

Cruickshank and Wright.-Filariasis in Cochin. Ind.Jl. of Med. Res., Vol. I, No. 4, 1914.

Brug.-Filaria Malayi N. Sp. Parasitic in Man in the Malay Archipelago. Trans. Far. E. Cong. Trop. Med., Vol. III, 1927.

Mapleston.-A re-description of Wuchereria Bancrofti (Cobbold, 1877) with special reference to the tail in the male. Ind. Jl. Med. Res., Vol. XVI, p. 683, 1929.

Iyengar.-Filariasis in North Travancore. Ind. Jl. Med. Res., Vol. XX, October, 1932.

Filariasis in Trivandrum. Ind. Jl. Med. Res., Vol. XX, April, 1933.

\section{CATHOLYSIS AS A NEW TECHNIQUE FOR OPERATIVE CLOSURE OF HOLES IN THE RETINA AND FOR TREATMENT OF ITS DETACHMENT}

\author{
BY \\ A. VogT \\ $z \ddot{U} \mathbf{R I C H}$
}

At the meeting of the Swiss Ophthalmological Society, May 4, 1934, Vogt reported for the first time on his new method of "catholysis." The apparatus generally used for electrolysis of the lashes can be employed. The anode is placed on the surface of the eye. The cathode is a very fine needle. After removal of the conjunctiva the spot is marked on the sclera with Indian ink. The needle cathode is passed through the sclera, deep enough to reach the detached retina. The application is very short. Galvanic current of 0.5 to 1 milliampères is used. The hole and its boundaries must be touched.

The method shows the following advantages in comparison with the galvano-cautery, the benzene-cautery and the caustic potash :-

1. Catholysis does the least damage. Cauterization produces temperatures of $500^{\circ} \mathrm{C}$. to $1,000^{\circ} \mathrm{C}$., caustic potash destroys the tissue to an uncontrollable extent; diathermy with 50 to 100 milliampères causes burns. The diathermic needle also pierces the detached retina in a dangerous and useless manner. The catholysis, 